\title{
ARTIGO
}

DOI: https://doi.org/10.22481/praxis.v15i31.4679

\section{CONCEPÇÕES DE DESENVOLVIMENTO INFANTIL: O QUE REVELAM PROFESSORAS E DOCUMENTOS OFICIAIS}

\author{
CHILD DEVELOPMENT CONCEPTIONS:
}

WHAT TEACHERS AND OFFICIAL DOCUMENTS REVEAL

\author{
CONCEPCIONES DE DESARROLLO INFANTIL: \\ QUÉ REVELAN PROFESORAS Y DOCUMENTOS OFICIALES
}

\begin{abstract}
Cíntia Resende Corrêa
Rede de Educação Básica Municipal de Uberaba - Brasil
\end{abstract}

Ana Maria Esteves Bortolanza

Universidade de Uberaba - Brasil

\begin{abstract}
Resumo: O objetivo deste artigo, parte de uma pesquisa, é analisar as concepções de desenvolvimento infantil de onze professoras de uma escola pública de Educação Infantil, situada no interior do estado de Minas Gerais e em documentos oficiais. Tem como foco identificar se as concepções de desenvolvimento infantil nos documentos e nas entrevistas com as professoras situam-se mais na esfera do cotidiano ou na esfera da atividade complexa. Trata-se de uma pesquisa qualitativa (2016), de abordagem histórico-cultural, tendo como foco o conceito de desenvolvimento infantil, atividade e linguagem como macrocategorias fundamentais para a compreensão do ser-criança. Os procedimentos metodológicos foram a entrevista e a análise de documentos oficiais. A análise dos documentos oficiais evidencia que o desenvolvimento infantil não é visto como um processo de todas as funções psicofisiológicas integradas da criança e relacionado ao processo de ensino e aprendizagem. Os resultados evidenciam que as professoras entrevistadas se apoiam mais em conceitos do cotidiano para sua atuação docente, o que aponta uma ausência de fundamentos teórico-metodológicos para nortear suas práticas pedagógicas em conhecimentos científicos. Infere-se que a formação docente, seja inicial ou continuada, precisa garantir aos professores a apropriação de conhecimentos científicos sobre a criança e seu desenvolvimento.
\end{abstract}

Palavras-chave: Desenvolvimento infantil; Práticas pedagógicas; Educação infantil.

\begin{abstract}
The purpose of this article, part of a research, is to analyze the conceptions of child development of eleven teachers of a public school of Early Childhood Education, located in the interior of the state of Minas Gerais and in official documents. It aims to identify if the conceptions of child development in the documents and in the interviews with the teachers are more in the daily sphere or in the sphere of the complex activity. This is a qualitative (2016), historical-cultural approach, focusing on the concept of child development, activity and language as fundamental macrocategories for the understanding of being-child. The methodological procedures were the interview and analysis of official documents. The analysis of the official documents shows that child
\end{abstract}


development is not seen as a process of all the integrated psychophysiological functions of the child and related to the process of teaching and learning. The results show that the teachers interviewed rely more on everyday concepts for their teaching performance, which points to an absence of theoretical and methodological foundations to guide their pedagogical practices in scientific knowledge. It is inferred that teacher training, whether initial or continuing, must guarantee to teachers the appropriation of scientific knowledge about the child and its development.

Keywords: Child development; Pedagogical practices; Child education.

Resumen: El objetivo de este artículo, parte de una investigación, es analizar las concepciones de desarrollo infantil de once profesoras de una escuela pública de Educación Infantil, situada en el interior del estado de Minas Gerais y en documentos oficiales. Tiene como foco identificar si las concepciones de desarrollo infantil en los documentos y en las entrevistas con las profesoras se sitúan más en la esfera de lo cotidiano o en la esfera de la actividad compleja. Se trata de una investigación cualitativa (2016), de abordaje histórico-cultural, teniendo como foco el concepto de desarrollo infantil, actividad y lenguaje como macrocategorías fundamentales para la comprensión del ser-niño. Los procedimientos metodológicos fueron la entrevista y el análisis de documentos oficiales. El análisis de los documentos oficiales evidencia que el desarrollo infantil no es visto como un proceso de todas las funciones psicofisiológicas integradas del niño y relacionado al proceso de enseñanza y aprendizaje. Los resultados evidencian que las profesoras entrevistadas se apoyan más en conceptos de lo cotidiano para su actuación docente, lo que apunta una ausencia de fundamentos teóricometodológicos para orientar sus prácticas pedagógicas en conocimientos científicos. Se deduce que la formación docente, sea inicial o continuada, debe garantizar a los profesores la apropiación de conocimientos científicos sobre el niño y su desarrollo.

Palabras clave: Desarrollo infantil; Prácticas pedagógicas; Educación Infantil.

\section{Introdução}

O artigo é resultado de parte de uma pesquisa qualitativa (2016), na perspectiva histórico-cultural, que trata sobre as concepções de desenvolvimento infantil, atividade e linguagem por meio de entrevistas com onze professoras de uma Escola de Educação Infantil, situada no interior do Estado de Minas Gerais. Entre as onze professoras, entrevistamos uma supervisora, uma gestora e nove educadoras ${ }^{1}$ de turmas de crianças de quatro meses a cinco anos. Na entrevista que foi realizada por escrito, as professoras responderam a três questões: O que é desenvolvimento infantil para você? Como você define a atividade na Educação Infantil? Qual é o papel da linguagem no desenvolvimento da criança? Neste artigo, o objetivo foi compreender as concepções de desenvolvimento infantil que, provavelmente, norteiam suas práticas pedagógicas, identificando as possíveis relações entre os documentos

\footnotetext{
${ }^{1}$ Educadora é o termo empregado pela Secretaria de Educação Municipal da escola-campo para denominar as professoras que atuam em sala com as crianças.
} 
oficiais em que se apoiam as professoras para planejar e desenvolver as atividades pedagógicas com as crianças.

A hipótese que nos guiou é que as concepções das professoras participantes sobre o desenvolvimento infantil vêm se constituindo na esfera do cotidiano, ou seja, baseiam-se em conceitos empíricos, ainda que tenham valor como saberes construídos no cotidiano, precisam incorporar os conhecimentos científicos, princípios e fundamentos que são assimilados e objetivados na esfera complexa da atividade humana. Para alcançar a esfera complexa da atividade humana, é preciso alcançar o nível da não-cotidianidade no processo de apropriação e objetivação dos conhecimentos científicos. Portanto, é na esfera complexa que nos apropriamos de conceitos científicos de forma a superarmos o empirismo para alcançar as máximas qualidades humanas produzidas historicamente pelos homens, no campo das artes, ciências, técnicas etc.

$\mathrm{Na}$ análise dos dados, buscamos compreender o objeto segundo os princípios teóricos de Vigotski (2010) que se referem à análise do processo, de forma a centrar-se na essência do fenômeno, e não em sua aparência. Portanto, a coleta e a análise dos dados coletados visaram a explicar o fenômeno para além da descrição, para alcançar o nível explicativo. Para comparar os dados das entrevistas e documentos oficiais, utilizamos como descritores na análise documental as três categorias exploradas nas entrevistas: o desenvolvimento, a atividade e a linguagem. O levantamento das concepções de desenvolvimento infantil, atividade e linguagem nos documentos oficiais - Matrizes Curriculares para a Rede Municipal de Ensino de Uberaba, Projeto Político-Pedagógico, Plano Anual de Ensino do Pré II - foi realizado por meio de descritores que correspondem às concepções das professoras pesquisadas neste estudo, consequentemente, são as três macrocategorias de análise.

Quando falamos em desenvolvimento infantil nos referimos à formação das funções psíquicas superiores da criança que têm uma base biológica mas não se desenvolvem de maneira autônoma. São construídas ao longo da história humana (filogênese) e da história individual (ontogênese). Ou seja, o desenvolvimento resulta da vida social, e não biológica, por isso que o biológico é condição, porém não basta para o desenvolvimento humano.

Para Leontiev (2006, p. 77):

[...] qualquer função se desenvolve e é reestruturada dentro do processo que a realiza. As sensações, por exemplo, incrementam-se em conexão com o desenvolvimento dos processos de percepção dirigidos por um alvo. É por isso que elas podem ser ativamente cultivadas em uma criança, e seu cultivo 
não pode, de mais a mais, em virtude disso, consistir em um treinamento simples e mecânico das sensações em exercícios formais.

Posto isso, compreendemos que é nas relações sociais, por meio da atividade, que a criança apropria-se da cultura e aprende a ser humana tendo como instrumento mediador a linguagem. Ou seja, é por meio das relações com outras pessoas que se constrói a si mesma. Portanto, a atividade na Educação Infantil deve trazer as máximas qualidades humanas do mundo da cultura para a humanização da criança.

De acordo com Pasqualini (2010, p. 166), “o desenvolvimento infantil não é determinado por leis naturais universais", vincula-se "às condições objetivas da organização social” apontando “a impossibilidade de se estabelecer estágios do desenvolvimento psicológico que se sucedam em uma ordem fixa e universal, válida para toda e qualquer criança em todo e qualquer contexto e a qualquer tempo". Nesse sentido, as funções psíquicas superiores desenvolvem-se culturalmente, e, portanto, o ensino é sua mola propulsora. Para isso, faz-se necessário criar as condições educativas adequadas para esse desenvolvimento da criança, sem o qual ela não se apropria das formas superiores de conduta.

\title{
Formação de professores para a Educação Infantil
}

Magalhães (2014, p. 15) nos explica a necessidade de pensarmos uma lógica que reoriente o pensar e agir do professor.

\begin{abstract}
A educação é uma objetivação da esfera da atividade não cotidiana, da esfera complexa da atividade humana. Por isso, é uma atividade que exige reflexão, intenção, fundamentação teórica. No entanto, a lógica que tem orientado o trabalho docente é a lógica do cotidiano. A questão estaria, então, em encontrar formas de impactar positivamente a compreensão do professor numa perspectiva de transformação da lógica que orienta seu pensar e agir na escola da infância.
\end{abstract}

Trabalhar, pedagogicamente, orientando-se pela lógica da atividade não cotidiana, exige não apenas apropriar-se de uma fundamentação teórico-metodológica que subsidie a prática pedagógica. É necessária também a compreensão de que o trabalho pedagógico deve ser um trabalho livre, criativo, para o professor fazer as escolhas teórico-metodológicas que melhor respondam às necessidades de seus alunos.

A objetivação está ligada às atividades, entretanto, as objetivações são, de acordo com Heller (1991) citada por Toassa (2005, p. 225) são "sempre genéricas e encarnam diferentes tipos de genericidade. Não são simplesmente as consequências das ações 
exteriorizadas, mas sistemas de referência quanto às atividades do homem". Objetivamos nossas atividades e comportamentos como produto do gênero humano, por meio de objetivações classificadas como em-si e para-si. As objetivações em-si são as da vida cotidiana que se referem aos usos e costumes como linguagem, costumes, objetos. Essa objetivação não exige uma relação consciente, por isso dizemos que é alienada em relação às formas mais elaboradas de cultura no processo de humanização.

Quanto às objetivações para-si, realizam-se no nível não cotidiano tornando a relação consciente com a vida cotidiana, ou seja, "Com a mediação das objetivações genéricas, tal relação simboliza a transformação do indivíduo em sujeito consciente das condições sociais que determinam sua existência e são por ele determinadas: processo de constituição da individualidade para-si”, segundo Duarte (2013, p. 99). As atividades da criança para a reprodução de si mesma são as cotidianas. Como exemplo podemos citar as atividades de vestir-se, escovar os dentes, atender a um telefonema, comunicar-se oralmente e tantas outras. Assim, na escola da infância faz-se necessário que o professor possibilite às crianças constituírem a individualidade para-si.

Para Duarte (2013, p. 103),

[...] o convívio social cotidiano, numa sociedade tão complexa, não dá conta da plena reprodução, em cada indivíduo, da humanidade produzida historicamente. Surge, então, como atividade voltada intencionalmente para esse fim, a educação escolar - forma socialmente dominante de educação, à qual cabe a mediação entre a vida cotidiana dos indivíduos e sua participação nas esferas não cotidianas da atividade social

Nesse sentido, entendemos que a formação docente inicial e continuada deve propiciar aos professores fundamentos teórico-metodológicos relativos ao desenvolvimento da criança, a fim de que possam, articulando teoria e prática, planejar intencionalmente as atividades desenvolvidas na escola da infância. Assim, podemos organizar o ensino intencionalmente voltado para o desenvolvimento pleno das crianças na escola de Educação Infantil. Dessa forma, as crianças aprendem e, aprendendo, podem desenvolver suas funções psíquicas superiores.

Recorremos a Mello (2007, p. 12) que aponta aos professores a importância de

[...] uma teoria que permita compreender o desenvolvimento humano em sua complexidade possibilita ao professor fazer as escolhas envolvidas na prática docente, que, vale lembrar, é um trabalho livre, como são poucos na sociedade atual. Como o trabalho do artista, o trabalho docente é trabalho de criação, de eleição de caminhos, de construção de estratégias para a 
atividade - arrisco dizer - o mais nobre em nossa sociedade: a atividade de formação da inteligência e da personalidade de cada criança.

Tendo em vista a necessidade de o professor desempenhar o trabalho docente de forma criativa, apoiado em fundamentos teóricos e metodológicos, tendo em vista educar a criança, perguntamo-nos como as professoras vêm realizando essa tarefa na Educação Infantil. Na perspectiva da teoria histórico-cultural, a criança aprende a ser homem por meio da atividade mediada por alguém mais experiente, apropriando-se dessa maneira dos conhecimentos construídos historicamente. Mukhina (1996, p. 233) reafirma essa perspectiva teórica ao explicar que a criança "amplia seu círculo de conhecimentos, torna-se mais independente, estende os limites das relações familiares e estabelece comunicação com mais pessoas, principalmente com crianças da sua idade", evidenciando que é nas relações com o outro por meio da atividade externa que a criança aprende e constitui-se como sujeito singular e autônomo.

Partindo de uma concepção de criança como ser histórico-cultural, com uma capacidade ilimitada de aprender, é preciso, então, que a escola de Educação Infantil seja organizada para desenvolver suas potencialidades, tendo em vista uma Educação Desenvolvente.

De acordo com Repkin (2003, p. 5),

[...] a Educação Desenvolvente é o desenvolvimento do sujeito. Pode-se julgar o tipo de ensino por um único critério - a criança é um sujeito no processo de ensino? Se ela é um sujeito, então temos uma Educação Desenvolvente, se ela é um objeto no processo de ser ensinada, então não temos uma Educação Desenvolvente. Educação Desenvolvente ocorre quando o parceiro do professor não é um estudante [no sentido de um objeto do ensino], mas um autoprofessor, um professor de si mesmo. Não é o professor que ensina o aluno, mas o aluno que ensina a si mesmo. E o papel do professor é ajudar o estudante a ensinar-se a si mesmo.

Em uma Educação Desenvolvente, a criança é sujeito ativo no processo de ensino, um tipo de professor de si mesma, como explica Repkin, cabendo ao professor organizar, planejar e desenvolvam um ensino em que ela ensina a si própria, diferentemente do aprender a aprender tão presente nos discursos e práticas de professores ainda hoje. A Educação Desenvolvente deve partir de tarefas que mobilizem no sujeito em formação a necessidade de aquisição de conhecimento, de resolução de problemas, para que o aluno seja responsável por sua própria aprendizagem. Nesse sentido, a formação dos professores precisa respaldar um ensino que promova a aprendizagem da criança como motor de seu desenvolvimento, diferentemente do que dizem as teorias interacionistas, particularmente a teoria construtivista 
de Piaget. Que desenvolvimento seria esse que requer a inserção da criança no mundo da cultura não em uma interação direta e natural, mas mediada pela atividade humana que tem na linguagem seu principal instrumento cultural.

Duarte esclarece que, nos estudos de Vigotski e seus seguidores, o desenvolvimento do indivíduo, isto é,

[...] a ontogênese humana não pode ser explicada através da relação biológica entre organismo e meio. A questão que não pode ser esquecida é a de que o modelo biológico de interação entre organismo e meio implica as noções de adaptação e equilíbrio na relação do organismo com o meio ambiente (sem o que o organismo não sobrevive). O modelo de interação entre organismo e meio não possibilita a compreensão da relação históricosocial entre objetivação e apropriação, que caracteriza a especificidade do desenvolvimento humano. (DUARTE, 2013, p. 107-108).

Diferentemente da teoria piagetiana, que elege a maturação biológica como condição para o desenvolvimento da criança preponderando os fatores internos nesse processo, Vigotski assevera que é o meio social a condição primeira para a criança desenvolver-se, ainda que ambos partam da ideia de criança como ser ativo, seguem diferentes caminhos: Piaget traça uma linha universal e fixa de desenvolvimento em estágios, contrariamente, Vigotski aponta para um processo de desenvolvimento dinâmico, de evoluções e involuções, em atividades primeiramente externas para atividades internas de formação das funções psíquicas superiores.

[...] um processo dialético que se distingue por uma complicada periodicidade, a desproporção no desenvolvimento das diversas funções, as metamorfoses ou transformações qualitativas de umas formas em outras, o entrelaçamento complexo de processos evolutivos e involutivos, o complexo cruzamento de fatores externos e internos, um complexo processo de superação de dificuldades e de adaptação. (VIGOTSKI, 2000, p. 141).

Ressaltamos que a atividade interna, mental da criança não é isolada de sua atividade externa, prática, pois são as relações sociais que podem favorecer seu desenvolvimento multilateral. Leontiev (1983) conceitua o trânsito multilateral como o movimento da atividade externa para a interna e da atividade interna para a externa, fundamental na atividade humana objetal, pois "a atividade interna, por sua forma, origina-se a partir da atividade prática externa, não se separa dela, conservando uma relação fundamental e bilateral com a mesma." (LEONTIEV, 1983, p. 62).

Assim, para Vigotski e seus seguidores, as funções psíquicas superiores têm uma base biológica, mas insuficiente para se desenvolver de maneira autônoma, são construídas ao longo da história humana (filogênese) e da história individual (ontogênese). Ou seja, o 
desenvolvimento resulta da vida social, e não biológica, por isso que o biológico é condição, porém não basta para o desenvolvimento humano.

Mello (2010, p.1) tem apontado em seus estudos que:

Muito do que temos feito com a educação das nossas crianças carece de uma base científica e que, frente aos novos conhecimentos que temos hoje e que já nos permitem falar em uma nova ciência - a ciência da educação podemos perceber alguns equívocos nas práticas que muitos de nós realizamos na educação das crianças.

Por isso, a importância de organizar a escola da infância como espaço educacional em que a criança é concebida como sujeito da atividade, com capacidades múltiplas de se apropriar de objetos e de fenômenos do mundo da cultura por meio da atividade de aprendizagem, educando-a. Em vista disso, é preciso que a escola de Educação Infantil seja organizada para desenvolver as potencialidades das crianças no processo de apropriação das máximas qualidades, isto é, das formas mais elaboradas de cultura a serem objetivadas, expressando-se por meio de múltiplas linguagens.

Não há como planejar uma Educação Infantil pautada no compromisso pela cidadania, para uma educação transformadora, sem pensar na formação do professor, pois ela é fundamental para organizar o trabalho educativo de maneira a impulsionar o desenvolvimento infantil por meio de desafios que levem as crianças a avançar nesse processo aprendizagem.

Cabe, portanto, ao professor, auxiliar, orientar a criança, no processo de educá-la e ensiná-la. Mukhina (1996, p. 40) esclarece como se realiza esse processo:

As crianças assimilam esse mundo, a cultura humana, assimilam pouco a pouco as experiências sociais que essa cultura contém, os conhecimentos, as aptidões e as qualidades psíquicas do homem. É essa a herança social. Sem dúvida, a criança não pode se integrar na cultura humana de forma espontânea. Consegue-o com a ajuda contínua e a orientação do adulto - no processo de educação e ensino.

As atividades planejadas e desenvolvidas pelo professor, sendo adequadas a cada idade de desenvolvimento da criança, favorecem a aprendizagem de novos conhecimentos, estimulam a curiosidade e a criatividade, pois toda atividade que é realizada pelas crianças, a partir de suas necessidades é aquela que coincidindo com os objetivos propostos pela professora tem significado para as crianças. A isso chamamos atividade significativa.

Por conseguinte, compreendemos como o trabalho pedagógico do professor torna-se essencial na Educação Infantil cujo objetivo é o desenvolvimento integral da criança. $\mathrm{O}$ 
professor é o principal mediador para impulsionar esse desenvolvimento, ao proporcionar às crianças o acesso à cultura que possibilita a apropriação de objetos e instrumentos culturais em suas máximas qualidades, como por exemplo a linguagem que é um instrumento cultural complexo. Para isso, é preciso que o professor assuma a condição de sujeito de sua prática pedagógica, aquele que diante de cada situação reflete, interroga-se, busca soluções, constrói novas estratégias, toma decisões; enfim, tem autonomia intelectual para planejar e executar seu trabalho pedagógico. Assumir essa condição exige estudo, pesquisa, reflexão sobre sua ação, autoavaliação, trabalho em parceria, intencionalidade e, principalmente, disponibilidade para aprender, experimentar, avaliar, fazendo as escolhas teórico-metodológicas que respondam às exigências de seu trabalho com as crianças.

Em um ensino intencionalmente planejado, o professor organiza o trabalho educativo sustentado por um conjunto de subsídios teórico-metodológicos, norteadores de sua atuação docente, de forma a evitar práticas baseadas no empirismo, norteadas pela lógica do cotidiano, ainda que necessárias e importantes. Nesse sentido, os fundamentos teórico-metodológicos são indispensáveis para a prática docente, o que implica em objetivação da atividade nãocotidiana, ou seja, organizar o trabalho docente tendo em vista a esfera complexa da atividade humana.

O desenvolvimento da criança, na perspectiva vigotskiana, está diretamente ligado ao desenvolvimento da sua atividade cultural, sendo primordial o papel do professor para que ela se desenvolva plenamente no processo de apropriação das formais mais elaboradas de cultura. O ensino planejado para que as crianças realizem atividades significativas, que desenvolvem suas funções psíquicas superiores, tem grande relevância na perspectiva histórico-cultural. Ainda que não seja o único responsável pelo desenvolvimento da criança, um ambiente escolar bem organizado e um ensino intencional na esfera da atividade complexa em que estão presentes as formas culturais mais elaboradas, é especial e bastante propício para o desenvolvimento infantil.

\section{As concepções das professoras sobre desenvolvimento infantil}

Vejamos o que dizem as professoras da escola-campo sobre o desenvolvimento da criança:

A professora $\mathrm{Ana}^{2}$ vê o desenvolvimento infantil como uma sequência de transformações nos aspectos físicos, emocionais e cognitivos. Semelhante a esta concepção, a

\footnotetext{
${ }^{2}$ As professoras receberam nomes para não serem identificadas, de forma a preservarmos seu anonimato.
} 
professora Corina afirma ser uma sucessão de etapas ou fases, nas quais ocorre uma série de mudanças físicas e psicológicas, que implicam no crescimento da criança. Também a professora Elvira conceitua como fases pelas quais a criança passa onde ela amadurece $e$ alcança determinados conjuntos de conceitos sendo que a criança alcança mais e aprimora as habilidades e competências. Já a professora Fátima cita Piaget, ao afirmar que o desenvolvimento ocorre por estágios e como ele mesmo diz pode variar de criança para criança. Desenvolver é conseguir realizar hoje coisas que não realizava ontem. A professora Helena aborda como as fases de crescimento da criança que passam por mudanças físicas e psicológicas alterando o afetivo e cognitivo da mesma. A professora Gertrudes define o desenvolvimento infantil como etapas que a criança desenvolve a partir do momento do seu nascimento. A professora Irene entende como a fase das descobertas, das curiosidades, do desenvolvimento lúdico e contínuo. É a fase da estimulação. A professora Kátia identifica desenvolvimento infantil com a ampliação de conhecimentos em que desde o nascimento a criança aprende a sugar o leite materno, onde se inicia a aprendizagem da afetividade.

As respostas das professoras à concepção de como as crianças se desenvolvem mostrou um cenário em que o desenvolvimento é visto como herança biológica, na relação estímulo-reação entre a criança e o ambiente, linear que foi descrito por elas em fases, transformações, etapas, estágios, em diferentes aspectos que podem ser emocionais, físicos, cognitivos. As professoras falam em crescimento e amadurecimento da criança, descobertas das crianças, lúdico como sinônimo de desenvolvimento, e até em fase de estimulação. Entretanto, essas respostas das professoras não relacionam o desenvolvimento da criança à formação de suas funções psíquicas superiores, como um processo que se realiza da atividade externa para a atividade interna e vice-versa, também não explicam como a criança se desenvolve enquanto processo que, necessariamente, precisa ser mediado.

Ao tratar sobre o desenvolvimento infantil, Vigotski (2000) diferencia as funções psicológicas elementares, conceituando-as como aquelas comuns aos homens e aos animais, como atenção e memória involuntárias; das funções psicológicas superiores que formam a atenção voluntária, a memória mediada, o pensamento abstrato, sendo sua gênese na atividade cultural. Isso significa que a função psicológica superior responde à exigência de um determinado comportamento presente na atividade social, são, portanto, formadas no processo educativo, seja ele formal ou informal.

As funções psíquicas superiores são adquiridas ao longo da vida no processo de apropriação da cultura, a herança biológica não é suficiente para a formação da personalidade 
do indivíduo. Magalhães (2014) aponta o papel primordial da atividade social no desenvolvimento infantil, ao afirmar que "[...] O psiquismo humano se desenvolve por meio da atividade social, atividade esta mediada por instrumentos como traço principal, interpondose entre o sujeito e o objeto de sua atividade [...]". Nessa perspectiva, o desenvolvimento infantil se faz primeiramente na atividade social, portanto, na atividade externa para realizarse na atividade internada criança de maneira a tornarem seus os conhecimentos apropriados nas relações interpsíquicas.

Isto posto, compreendemos que por meio da atividade na esfera complexa a criança se apropria da cultura e constitui-se como sujeito para-si, pois ao relacionar-se com outras pessoas constitui a si mesma. Portanto, se queremos que as crianças se desenvolvam plenamente, temos que planejar as atividades na Educação Infantil buscando as formas elaboradas da cultura.

\section{O papel do meio no desenvolvimento da criança}

O meio não deve ser entendido, segundo Vigotski (2010), por meio de parâmetros absolutos, mas a partir de parâmetros relativos; isto é, precisamos considerar o meio como uma "circunstância do desenvolvimento, por encerrar [...] qualidades ou determinadas características que já propiciam, por si próprias, o desenvolvimento da criança” (VIGOTSKI, 2010, p. 682). O meio influencia diferentemente dependendo da idade em que a criança se encontra e das relações que ela estabelece nesse meio em que está inserida. $O$ desenvolvimento da criança consiste justamente na ampliação gradativa do meio: família, vizinhos, escola, sociedade etc. Ainda, segundo o autor, esse papel é tão forte que, com o passar dos anos, os significados dos elementos que compõem o meio, por mais que permaneçam inalterados, são interpretados de maneira diferente pela criança, pois sua relação se modifica conforme o estágio de desenvolvimento.

Assim podemos inferir que a influência do meio no desenvolvimento da criança é resultado de suas vivências. Para Vigotski (2000, p. 683-684), vivência "não é esse ou aquele elemento tomado independentemente da criança, mas, sim, o elemento interpretado pela vivência da criança que pode determinar sua influência no decorrer do seu desenvolvimento futuro"

Em relação ao papel do meio no desenvolvimento infantil, vejamos o que dizem as professoras: A professora Ana diz que a criança necessita de um ambiente acolhedor, harmonioso e rico em experiências, seja na escola ou no lar, destacando que "a criança 
deverá se sentir protegida e acolhida, sendo família é o primeiro ponto em que a criança irá se desenvolver. Para a professora Beatriz afirma que a criança precisa de um ambiente acolhedor, tranquilo e agradável. Também a professora Janete reforça a necessidade de um ambiente harmonioso, acolhedor e rico em experiências desde o pré-natal por meios de cuidados com a mãe e seu ambiente e continuar a ser promovido de forma intensiva após o nascimento. Para a professora Janete é muito importante a participação da família e da escola para que a criança se desenvolva integralmente. A professora Beatriz aponta que é necessário que seja um trabalho em conjunto (escola e família), assim o desenvolvimento será melhor. De acordo com a professora Irene, o desenvolvimento infantil depende de situações sociais, [em] que as crianças começam a estabelecer vínculos afetivos, tanto com adultos, quanto com outras crianças. A professora percebe o desenvolvimento infantil como fases em que "a criança é estimulada através do seu meio social.

Embora as professoras, participantes da pesquisa, apontem o papel do meio na vida da criança como uma condição para seu desenvolvimento, não conceituam meio nem explicam como ele pode influir no desenvolvimento da criança, ou seja, que relações a criança estabelece e, como nesse processo pode formar sua personalidade, desenvolvendo suas funções psíquicas superiores.

Para impulsionar o desenvolvimento da criança, de acordo com Vigotski (2000), o professor precisa trabalhar atividades que elas ainda não conseguem realizar sozinhas, mas poderão fazê-las com a mediação da professora, ou seja, nessa situação, o ensino atua na zona de desenvolvimento iminente da criança, levando-a a avançar para realizar o que ela ainda não consegue fazer sozinha, mas fará no futuro.

Um ensino orientado até uma etapa de desenvolvimento já realizado é ineficaz do ponto de vista do desenvolvimento geral da criança, não é capaz de dirigir o processo de desenvolvimento, mas vai atrás dele. A teoria do âmbito de desenvolvimento potencial origina uma fórmula que contradiz exatamente a orientação tradicional: o único bom ensino é o que se adianta ao desenvolvimento. Vigotski (2000, p. 114). Se o professor se atém às atividades que as crianças conseguem realizar sozinhas, isto é, na zona de desenvolvimento real, elas irão permanecer no mesmo nível de desenvolvimento, não avançando para novas aprendizagens e, portanto, pouco avançando no desenvolvimento de suas funções psíquicas superiores. No processo educativo colaborativo, o professor e a criança caminham juntos na busca de novos conhecimentos científicos. 


\section{As concepções de desenvolvimento infantil nos documentos oficiais}

Foram dois os documentos oficiais analisados: as Matrizes Curriculares Municipais (2014) e o Projeto Político Pedagógico da escola-campo.

O documento norteador das professoras entrevistadas neste estudo, as Matrizes Curriculares $_{\text {Municipais }}{ }^{3}$ da escola-campo afirmam que o ensino

[...] "precisa deixar de ser uma transmissão de conhecimentos (verdades prontas), para constituir-se em processo de elaboração de situações didáticopedagógicas que facilitem a aprendizagem, isto é, que favoreçam a construção de relações significativas entre componentes de um universo simbólico" (MORETO, 2003). 'Ensinar não é transferir conhecimento, mas criar as possibilidades para sua própria produção ou sua construção. (FREIRE, 1996, p. 47). (MATRIZES MUNICIPAIS, 2014, p. 8).

O trecho acima citado das Matrizes Curriculares foi extraído, provavelmente, do artigo Avaliação escolar como processo de construção de conhecimento, de Édina Souza de Melo Wagner Gonçalves Bastos, e tem como objetivo analisar o processo de avaliação como construção de conhecimento pelo próprio aluno. De acordo com Bastos (2012), "Nessa relação, além de transmissor de informações, o professor é o elemento mediador (catalisador) da interação entre o aluno e o conhecimento socialmente construído, cabendo a ele a função de criar as condições mais favoráveis à aprendizagem do aluno". Perguntamo-nos: Seria função do professor transmitir informações? O professor é o elemento mediador quando cria condições de aprendizagem? Isso bastaria para que as crianças se apropriassem do mundo da cultura?

O conceito de mediação em contextos escolares necessita ser revisto por outros olhares teóricos, pois interpretações equivocadas resultam cada vez mais no descolamento de seu significado conceitual nas práticas pedagógicas em sala de aula. Como ser histórico e social, inserido na cultura, o homem transforma a realidade e é por ela transformado no processo de apropriação e objetivação dos conhecimentos, nas relações que estabelece com o outro. Nesse processo, o papel da linguagem é fundamental como instrumento cultural complexo, ao mediar as relações do homem com o outro, com os objetos e fenômenos. Esse é o processo pelo qual a criança aprende e se desenvolve.

À vista disso, a ação de outras pessoas no desenvolvimento da criança é fundamental para mediar às aquisições dos conhecimentos historicamente construídos. Esse processo se

\footnotetext{
${ }^{3}$ As Matrizes Curriculares Municipais foram assim denominadas para não identificar a Rede Municipal de Educação responsável pelo documento. Não constam das referências para preservar o anonimato da escola e da secretaria municipal de educação.
} 
realiza por meio da linguagem em suas relações com o pensamento, a consciência. Portanto, cabe ao professor organizar, planejar, sistematizar, executar e avaliar o trabalho educativo com a finalidade de garantir às crianças a apropriação dos conhecimentos na atividade pedagógica.

Segundo Libâneo (2004), o conceito de mediação possibilita inferir que o professor cria os meios necessários para que as crianças possam se apropriar do mundo da cultura, a essa atividade denominamos atividade de ensino (LIBÂNEO 2004, p.5). Portanto, é no espaço escolar que podemos, ensinando, promover atividades de aprendizagem ao viabilizar às crianças os conteúdos do mundo da cultura.

Na introdução do documento, Matrizes Curriculares Municipais, apresenta-se uma organização curricular em que os conteúdos são vistos como meio para desenvolver as competências da criança, entendidas como capacidades construídas internamente pela criança madura. Embora o desenvolvimento infantil seja relacionado sob alguns aspectos com as brincadeiras, situações lúdicas, ele é vinculado à maturidade da criança, no sentido de que a criança primeiro precisa amadurecer para depois construir seus conhecimentos, num processo interno que exclui o papel da atividade externa como condição primeira para sua aprendizagem. Também é citada a avaliação diagnóstica das crianças para averiguar seu desenvolvimento psicomotor. A ênfase na motricidade, como está posto na situação de avaliação diagnóstica, limita-se a identificar a zona de desenvolvimento real da criança, ou seja, aquilo que ela faz com autonomia, sem precisar de auxílio de outros.

De acordo com Chaiklin (2011), a avaliação diagnóstica remete à zona de desenvolvimento real da criança, não apontando suas possibilidades de desenvolvimento potencial, ou seja, aquilo que a criança pode fazer com a ajuda de alguém mais experiente e que poderá fazer sozinha no futuro, condição para o professor organizar o trabalho educativo, situando o ensino intencionalmente na zona de desenvolvimento iminente que mostra o potencial de aprendizagem da criança.

O conceito de desenvolvimento é fortemente associado à maturação, sendo o professor a referência da criança nas situações lúdicas de aprendizagem. O emprego da palavra maturação parece referir-se à concepção piagetiana de desenvolvimento infantil como processo de amadurecimento de um organismo vivo, com base em suas condições biológicas, isto é, suas condições internas de amadurecimento. Nesses parágrafos, evidenciamos também, implicitamente, o conceito de desenvolvimento associado ao processo de aprendizagem por 
meio das atividades lúdicas, adjetivo empregado com o sentido de atividade de entretenimento.

Em síntese, os itens descritos no documento Matrizes Curriculares Municipais (2014) trazem implicitamente o conceito de desenvolvimento voltado para a perspectiva piagetiana, não como um processo dialético de desenvolvimento integrado da criança, de todas as funções psicofisiológicas, em relação umas com as outras e vistas em sua totalidade.

No documento Projeto Político Pedagógico ${ }^{4}$ (2014, p.6) da escola-campo, a criança em desenvolvimento é abordada como "sujeito responsável e capaz de desenvolver-se com consciência plena e eticamente atuante no processo de sua formação enquanto cidadão". Como aprendiz e agente de seu desenvolvimento, a criança deve desenvolve-se "como ser de conhecimento, leitor e intérprete arguto da realidade"; ser competente, "autor e ator criativo de alternativas face às diferentes demandas de transformações sociais; ser-de-convivência solidária, humanizador das relações interpessoais, ambientais e culturais; enfim, SER de Humanidade Plena, criador, lúcido e amoroso.

O desenvolvimento infantil apresentado parece associado aos estágios de desenvolvimento da criança como sujeito que se autodesenvolve, ou seja, que constrói sozinho o conhecimento, ao ser caracterizado como ser de conhecimento, leitor, intérprete da realidade, ser de competências, autor e ator, criador de alternativas, ser de convivências, ser solidário, humanizador, ser de humanidade plena. Menciona-se o desenvolvimento psicomotor da criança, sem relação como o processo de ensino e aprendizagem, sugerindo desenvolvimento como processo autônomo, interno, que independe das experiências vivenciadas pela criança em seu entorno e da relação que ela estabelece com o meio. Para Vigotski (2010), o desenvolvimento infantil é visto como uma abordagem que visa a evolução e revolução, formas encadeadas e recíprocas nas quais todas as funções se formam em relação umas com as outras por meio de atividades significativas, em que o professor ensina às crianças os conteúdos mediados pela linguagem, instrumento cultural complexo.

No planejamento, o desenvolvimento da criança é tomado como uma categoria para definição do desenvolvimento real das crianças, assim sendo, não incide em sua zona de desenvolvimento iminente que dimensiona o que a criança é capaz de fazer com a ajuda de alguém mais experiente e, portanto, fará sozinha no futuro. Não sendo processual nem contínuo, não explicita como a criança se desenvolve integralmente em todos os aspectos da sua personalidade. Nesse sentido, o conceito mais uma vez aparece descolado do processo de

\footnotetext{
${ }^{4}$ O Projeto Político Pedagógico não foi referenciado para não identificar a escola-campo, preservando assim seu anonimato.
} 
ensino e aprendizagem, que, segundo a perspectiva histórico-cultural, impulsiona o desenvolvimento integral.

Tendo em vista os conceitos de níveis de desenvolvimento e sua relação com os processos de ensino e aprendizagem, constatamos que nos documentos oficiais estão ausentes esses elementos que poderiam contribuir para a organização do trabalho pedagógico com foco no ensino intencional para uma aprendizagem significa, como condição para o desenvolvimento integral da criança.

\section{Considerações finais}

O conceito de desenvolvimento infantil, no Projeto Político Pedagógico, embora seja qualificado como integral e processual, não explica claramente o que seria esse desenvolvimento integral e processual. Nas Matrizes Curriculares Municipais (2014), as concepções de desenvolvimento infantil trazem o conceito de desenvolvimento infantil mais voltado para a perspectiva piagetiana, e não são apresentados os fundamentos que caracterizam o desenvolvimento da criança nessa perspectiva. As professoras deste estudo refletem em suas concepções sobre o desenvolvimento infantil os documentos oficiais, de tal forma que podemos inferir que suas práticas pedagógicas são demarcadas por esses documentos oficiais. Assim, consideramos que não se toma o desenvolvimento infantil como um processo dialético de desenvolvimento integrado da criança, de todas as funções psicofisiológicas, em relação umas com as outras e vistas em sua totalidade, nas relações interpsíquicas em atividades externas e, nas relações intrapsíquicas em atividades internas. Sem um conjunto sólido de fundamentos teóricos e metodológicos para organizar o trabalho educativo, as professoras reproduzem, de forma alienada em suas práticas pedagógicas conteúdos da lógica do cotidiano. $\mathrm{O}$ ato de educar situa-se na esfera complexa da atividade humana. Isso exige do professor reflexão, intenção e fundamentação teórica. É preciso articular os conhecimentos do cotidiano com os conhecimentos científicos para inverter a lógica que tem dominado muitas escolas de Educação Infantil e assim orientar o pensamento do professor e sua atuação docente para uma educação humanizadora, que transforme a escola da infância.

Ressaltamos a relevância da concepção de desenvolvimento humano na perspectiva histórico-cultural que traz contribuições científicas significativas ao explicar como se desenvolvem as funções superiores da criança, focando sua origem histórica e social, pois nascem e se desenvolvem nas relações sociais que a criança estabelece em sua infância na 
sociedade. Como vimos, ao partir do pressuposto da constituição social das funções psíquicas superiores, Vigotski se contrapõe às teorias mecanicistas e naturalistas, destacando nesse processo que o desenvolvimento cultural da criança depende diretamente de suas condições de vida e educação.

Nessa perspectiva, o professor assume um compromisso com a educação que é político-pedagógico, segundo Mészáros (2005), capaz de avançar para criar uma alternativa educacional que supere a lógica do capital, uma educação efetivamente humanizadora.

\section{REFERÊNCIAS}

MELLO, Edina Souza de. BASTOS, Wagner Gonçalves. Avaliação escolar como processo de construção do conhecimento. Est. Aval. Educ., São Paulo, v. 23, n. 52, p. 180-203, maio/ago. 2012.

CHAIKLIN, Seth. A zona de desenvolvimento próximo na análise de Vigotski sobre aprendizagem e ensino. Tradução de Juliana Campregher Pasqualini. Psicologia em Estudo, Maringá, v. 16, n. 4, p. 659-675, out./dez. 2011.

DUARTE, Niwlton. A individualidade para si. 3. Ed. Campinas, SP: Autores Associados, 2013

LEONTIEV, Alexei Nikolaevich. El problema de la actividad en la psicología. La Habana: Pueblo y Educación, 1983.

LEONTIEV, Alexis Nikolaevich. N. Uma contribuição à teoria do desenvolvimento da psique infantil. In: VIGOTSKI, L. S.; LURIA, A. R. Linguagem, desenvolvimento e aprendizagem. São Paulo: Ícone, 2006.

LIBÂNEO, José Carlos. A didática da aprendizagem do pensar e do aprender: A teoria Histórico-Cultural da Atividade e a contribuição de Vasili Davydov. Rev. Bras. Educ., v. 27, set. / out./ nov./dez. 2004.

MAGALHÃES, Cassiana. Implicações da teoria histórico-cultural no processo de formação de professores da educação infantil. Tese (Doutorado em Educação) - Faculdade de Filosofia e Ciências, Universidade Estadual Paulista, Marília, 2014.

PASQUALINI, Juliana Campregher. O papel do professor e do ensino na educação infantil: a perspectiva de Vigotski, Leontiev e Elkonin MARTINS, Lígia Márcia e DUARTE, Newton. (Org). Formação de professores: limites contemporâneos e alternativas necessárias [online]. São Paulo: Editora UNESP; São Paulo: Cultura Acadêmica, 2010.

MELLO, Suely Amaral. Infância e Humanização: algumas considerações na perspectiva histórico-cultural. Perspectiva, Florianópolis, v. 25, n. 1. Jan./jun. 2007. 
MELLO, Suely Amaral; FARIAS, Maria Auxiliadora. A escola como lugar de cultura mais elaborada. Educação, Santa Maria, v. 35, n. 1, p. 53-68, jan./abr. 2010 Disponível em:

$<$ http://www.ufsm.br/revistaeducacao

MUKHINA, Valéria. Psicologia da idade pré-escolar. São Paulo: Martins Fontes, 1996.

REPKIN, Vladimir Vladimirovich. Journal of Russian and East European Psychology, v. 41, no. 4, july-august, 2003.

VIGOTSKI, Lev Semyonovich. Obras escogidas. Madri: Visor, 2000.

VIGOTSKI, Lev Semynovich. A construção do pensamento e da linguagem. Martins Fontes: São Paulo, 2010.

\section{$\underline{\text { SOBRE AS AUTORAS }}$}

\section{Cíntia Resende Corrêa}

Mestre em Educação pela Universidade de Uberaba (UNIUBE). Professora da educação básica da Secretaria Municipal de Educação de Uberaba, MG. Pesquisadora do Grupo de Estudos e Pesquisas Infância e Contextos Educativos - GEPICE. Email: cintia.correa@uniube.br

\section{Ana Maria Esteves Bortolanza}

Doutora em Educação Brasileira pela Universidade Estadual "Júlio de Mesquita Filho" (UNESP). Pós-Doutora em Educação pela Universidade de Évora (Portugal). Docente do Programa de Pós-Graduação em Educação da Professora da Universidade de Uberaba (UNIUBE). Líder do Grupo de Estudos e Pesquisas Infância e Contextos EducativosGEPICE. Email: amebortolanza@uol.com.br 